\title{
SIMULATION OF PRIMARY PRODUCTION IN EVEN-AGED STANDS OF DOUGLAS FIR
}

\author{
G.M.J. MOHREN, C.P. VAN GERWEN and C.J.T. SPITTERS
}

Department of Theoretical Production Ecology, Agricultural University, Wageningen, P.O. Box 430, 6700 AK Wageningen (The Netherlands)

(Accepted 5 January 1984)

\section{ABSTRACT}

Mohren, G.M.J., Van Gerwen, C.P. and Spitters, C.J.T., 1984. Simulation of primary production in even-aged stands of Douglas fir. For. Ecol. Manage., 9: 27-49.

Net primary production in even-aged stands of Douglas fir (Pseudotsuga menziesii (Mirb.) Franco) in The Netherlands is simulated from stand establishment after planting until harvest time. Net yearly increments of needle, branch, stem and root biomass are calculated from gross primary productivity, determined by weather conditions, photosynthetic performance of the foliage, site index, and biomass-dependent maintenance respiration. Stand structure is represented by an array of stem diameters at breast height, based on 20 percentiles of the cumulative diameter frequency distribution. Individual tree-to-tree distances are not taken into account. Spatial arrangement of the trees is assumed to be optimal with respect to interception of incoming radiation. The model incorporates a thinning management algorithm which provides for several types of thinning. Comparison of the behaviour of the model with measurements from permanent field plots in The Netherlands shows acceptable agreement of the simulation results with the experimental data. Using a simulation model, a wide variety of environmental factors combined with different management alternatives can be evaluated for their influence on forest primary production.

\section{INTRODUCTION}

Forest primary production is influenced by interacting weather conditions such as temperature and incoming radiation, species characteristics such as the photosynthetic capacity of the foliage, site characteristics such as water availability and nutrient status, and stand architecture which determines the degree to which the site is occupied. In order to understand the importance of each of these aspects for the dynamics of primary productivity and stand growth, it is convenient to relate them in a general ecosystem context, which gives an overall view of stand behaviour, based on functional relationships. Based on this understanding it is possible to analyse the response of the biological production system to changes in environmental variables, to detect the main limiting growth factors on certain 
sites, and to evaluate the effects of management alternatives. The advantage of ecosystem analysis combined with simulation to assess the behaviour of the system, is that assumptions concerning system boundaries, and knowledge of assumed internal relationships, must be formulated explicitly and their consequences can be checked. Comparison of the simulation results with the behaviour of the real-world system yields information on the validity of the underlying assumptions. In this way, by constructing and evaluating the model, simulation contributes to the understanding of the system, and helps to define the areas where research is most needed.

In the case of forestry, dynamic system simulation in which ecophysiology is linked to practical forestry is particularly interesting as it provides an opportunity to evaluate the consequences of long-term processes on productivity, which may help to define possibilities for increasing total yield. Taking into account the high costs and long periods of time involved in establishment and subsequent measurement of permanent field plots, simulation can be a valuable tool in growth and yield research. In this paper a pilot model is presented for even-aged stands of Douglas fir (Pseudotsuga menziesii (Mirb.) Franco) in The Netherlands. In a broader perspective, this model can be seen as a first attempt to quantify primary productivity based on physiological processes as reported by M $\phi$ ller (1945), Polster (1950) and Kira and Shidei (1967), using an approach developed in field crops (De Wit et al., 1978; Penning de Vries and Van Laar, 1982). Douglas fir has been chosen for the case study because of its increasing importance in European forestry.

\section{SIMULATION MODEL}

\subsection{General aspects and model structure}

Stand growth is estimated as the result of gross primary productivity determined by photosynthesis characteristics of the species, radiation climate, respiration needed to maintain the living biomass, and growth respiration to account for the conversion of assimilates into structural biomass. An example may help to illustrate this: gross primary productivity for a given site equals 48 ton $\mathrm{CH}_{2} \mathrm{O} \mathrm{ha}^{-1} \mathrm{yr}^{-1}$. Assume $40 \%$ of this (19 ton) is allocated to stem tissue. Ten percent of this fraction is needed for stem maintenance respiration, giving 17 ton net assimilate as increment. Growth respiration amounts to $35 \%$, which leads to a final stem increment of about 11 ton dry weight $\mathrm{ha}^{-1} \mathrm{yr}^{-1}$, or approximately $24 \mathrm{~m}^{3}$ stem volume increment at a specific gravity of 0.47 ton dry wt.m ${ }^{-3}$. Such a calculation of annual growth is also performed in the simulation model, but in much more detail. It is important to realise that all processes are assessed at the canopy and stand level, without much detail as far as individual trees are concerned. Growth and development are simulated from stand establishment after planting until possible harvest time. The model provides for thinning management. 


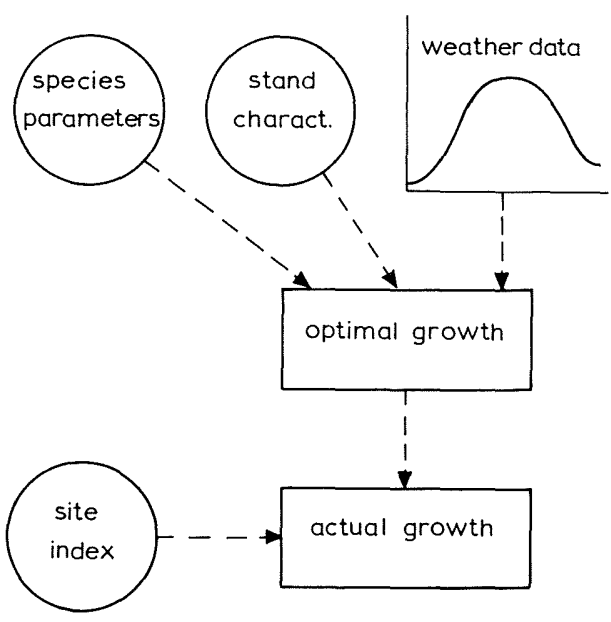

Fig. 1. Diagram showing the main conditions influencing primary production in a hierarchical arrangement. Site index (accounting for water and nutrients availability) is used to estimate actual growth from optimal primary production.

In the present version of the simulation model DOUGLA, optimum growth possible under prevailing weather conditions in The Netherlands is simulated using the deterministic approach outlined above. In order to be able to evaluate the model in relation to existing permanent field-plot measurements (some under clearly non-optimal conditions), an empirical site-specific reduction factor is applied in estimating actual gross photosynthetic production from the calculated potential production rate (Fig. 1). This reduction factor is deduced from the current forest yield tables for Douglas fir in The Netherlands (La Bastide and Faber, 1972), in which stand height is used to classify site productivity. In this way, non-optimal growing conditions for a site are accounted for in a rather superficial and empirical way, but the procedure allows a general comparison of the dynamics of simulated and actual growth.

In empirical forest growth and yield simulation models, growth is usually estimated for each individual tree, using, for example, the growth rate of open-grown trees as a potential growth rate. Actual growth rate in these models is calculated as a function of distance and size of neighbouring trees, site conditions, and the potential growth rate. Consequently, stand production is calculated by summing the growth rates of the trees which make up the stand (e.g. Alder, 1979; Alder and Schneider, 1979). In this bottom-up approach, the attention given to each tree determines the accuracy of the resulting stand-level estimate and the models can easily be classified according to the degree of sophistication in handling stand structure (Munro, 1974). In the modelling approach reported here a top-down design is used in that production is estimated on a stand level, e.g. on an areal basis. Afterwards, growth is allocated to the trees in the stand. This 

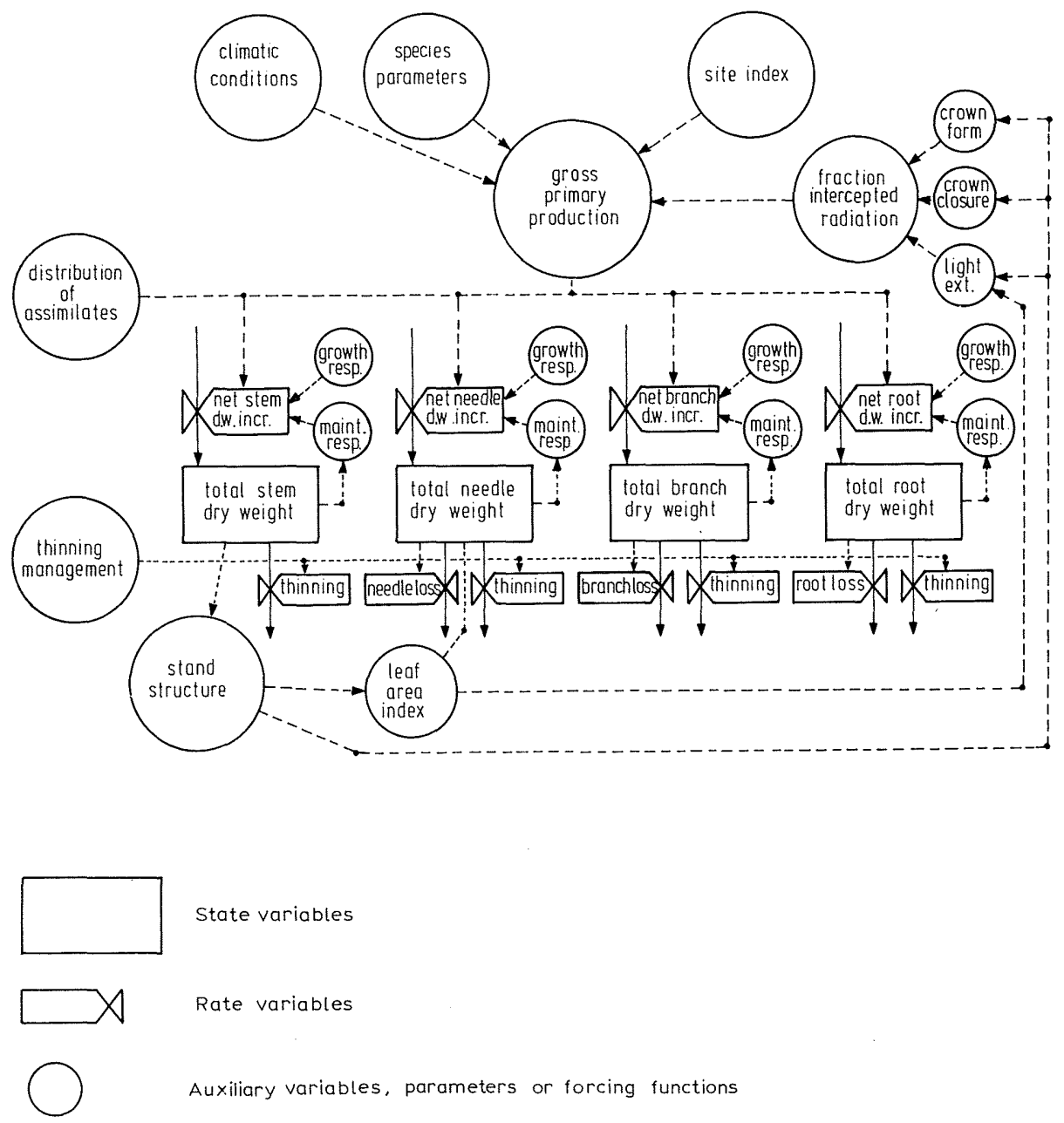

Fig. 2. Relational diagram for the simulation model DOUGLA. Solid lines: material flows (structural biomass). Dotted lines: information flows. In the diagram, thinning is represented by valve symbols, indicating the decrease of component dry weight, although this is not caused by a continuous flow but occurs at distinct intervals. If mortality (natural thinning) were to be incorporated this would have the same effect in the model.

implies that the estimate of primary production of the stand is less dependent on information about individual tree behaviour and stand structure.

The main focus of the modelling approach outlined above lies with processes at the stand or canopy level. The model can be seen as an explanation and prediction of processes at the canopy level, based on the underlying physiological processes at the organ level and, to a lesser extent, on the individual tree level. Individual tree level is used mainly to represent stand and canopy structure, in order to account for its effect on intercep- 
tion of incoming radiation. A relational diagram of the model, showing its overall structure, is given in Fig. 2. Gross primary productivity is treated in this model as an auxiliary variable. It may be seen as an input rate of assimilates into a reserve pool, from which assimilates for maintenance respiration and assimilates for structural dry matter increase are drawn. The present version of the model does not contain a state variable to represent a reserve pool, but assimilates are allocated directly to growth or respiration. Hence, maintenance respiration is represented in the same way as gross productivity - by an auxiliary variable.

The actual simulation of stand development is carried out by running a computer program of the model, formulated in CSMP (IBM, 1975). The simulation can be carried out in two ways, depending on the way of initialization. To simulate an existing plot, actual stand structure at the beginning of the simulation period is used as input; to simulate a hypothetical stand, stand structure is generated by the model at the beginning of a run. The present version of the model uses timesteps of one year. Maximum gross primary production is calculated from a model which simulates daily gross photosynthesis (Goudriaan and Van Laar, 1978), and is used here as a parameter with the dimension of ton $\mathrm{CH}_{2} \mathrm{O} \mathrm{ha}^{-1} \mathrm{yr}^{-1}$. The model can be used to simulate stand development for periods of up to 100 years.

\subsection{Potential productivity}

Potential productivity is the result of gross photosynthetic productivity, the conversion efficiency of photosynthates to structural biomass and maintenance respiration in a completely closed, green canopy, well supplied with water and nutrients, and in the absence of pests, diseases and weeds.

Gross photosynthetic production. Gross photosynthetic productivity can be estimated from the photosynthesis-light response curve of individual leaves at the ambient air temperature and $\mathrm{CO}_{2}$ concentration, combined with canopy architecture as far as amount and position of leaf surface is concerned, and weather conditions. From weather conditions total incoming photosynthetically active radiation is calculated using latitude, length of the growing season and degree of cloudiness (De Wit, 1965; Goudriaan and Van Laar, 1978). Using an asymptotic exponential equation for the photosynthesis-light response curve (Goudriaan and Van Laar, 1978; Goudriaan, 1979) leaf photosynthesis can be characterized by the photosynthetic efficiency at low light intensities - assumed in the model to be $14 \times 10^{-9} \mathrm{~kg} \mathrm{CO}_{2} \mathrm{~J}^{-1}$ - and the rate of photosynthesis at light saturation. This saturation value is assumed to be $15 \mathrm{~kg} \mathrm{CO}_{2} \mathrm{ha}_{\text {leaf }}^{-1} \mathrm{~h}^{-1}$ (Larcher, 1980). Daily gross photosynthesis for a given latitude (taken as $52^{\circ}$ Northern latitude for The Netherlands) can now be estimated using the tabulated data given by Goudriaan and Van Laar (1978), if the degree of cloudiness is known. Assuming the degree of cloudiness to be 0.4 , which means 0.4 
completely clouded and 0.6 completely clear, for a growing season of 200 days (11 April-17 October), total gross production during the season can be calculated by summing the values for the individual days. This results in an estimate for yearly gross production of 70 ton $\mathrm{CO}_{2} \mathrm{ha}^{-1}$, or 48 ton $\mathrm{CH}_{2} \mathrm{O} \mathrm{ha}^{-1}$. This value is used as input in the simulation model.

Distribution of assimilates. The gross assimilation can be regarded as a carbon pool, which has to be distributed or assigned to the separate biomass components of the stand. In the present version of the model, distinction is made between needle, branch, stem and root biomass. In this preliminary model carbon allocation is done assuming fixed distribution coefficients, independent of stand age or site quality, and equal to $0.25,0.10,0.40$ and 0.25 for needles, branches, stems and roots, respectively.

Maintenance respiration. To arrive at an estimate of net yearly increment for each biomass component, an amount of assimilate must be subtracted to account for maintenance respiration. Maintenance respiration is needed for maintaining living biomass, and depends on temperature and biomass composition, especially the amounts of relatively unstable components such as enzymes with high turnover rates. Maintenance respiration is estimated by multiplying current component biomass (ton ha ${ }^{-1}$ ) by a maintenance respiration coefficient $\mathrm{RC}_{i}$ (ton $\mathrm{CH}_{2} \mathrm{O}$ ton ${ }^{-1}$ dry wt. $\mathrm{yr}^{-1}$ ) for each biomass component. The coefficients used in the model are derived from available literature (Yoda et al., 1965; Penning de Vries, 1974, 1975; Kira, 1975; Yoda, 1978). The maintenance respiration coefficients used are 1 ton $\mathrm{CH}_{2} \mathrm{O}$ ton ${ }^{-1}$ dry wt. $\mathrm{yr}^{-1}$ for needle biomass, 0.08 ton $\mathrm{CH}_{2} \mathrm{O}$ ton ${ }^{-1}$ dry wt. $\mathrm{yr}^{-1}$ for branches, 0.025 ton $\mathrm{CH}_{2} \mathrm{O}$ ton ${ }^{-1}$ dry wt. $\mathrm{yr}^{-1}$ for stemwood, and 0.1 ton $\mathrm{CH}_{2} \mathrm{O}$ ton ${ }^{-1}$ dry wt. $\mathrm{yr}^{-1}$ for root biomass. The coefficient for stemwood is used for total living sapwood only; it is assumed that heartwood functions only as supporting tissue, and that it does not require any maintenance respiration. Total amount of sapwood is calculated by assuming a constant sapwood thickness of $5 \mathrm{~cm}$ on all parts of the bole.

Not too much physiological significance can be attributed to these values as they tend to cover up complex underlying processes. They must be viewed in combination with the distribution coefficients used and serve only to illustrate the magnitude of the processes.

Growth respiration. The resulting net yearly production for each biomass component is still expressed in ton $\mathrm{CH}_{2} \mathrm{O} \mathrm{ha}{ }^{-1}$, and has to be converted to structural dry weight increment. This is done by subtracting growth respiration in order to account for the loss of weight $\left(\right.$ as $\mathrm{CO}_{2}$ and $\left.\mathrm{H}_{2} \mathrm{O}\right)$ in the conversion process. Growth respiration can be estimated on the basis of the composition of structural biomass ultimately formed, e.g. fats and proteins being more 'expensive' to synthesize than starch and cellulose (Penning de Vries et al., 1974). For all biomass components, a conversion factor (DWC) of 0.65 ton dry wt. ton ${ }^{-1} \mathrm{CH}_{2} \mathrm{O}$ is used. 
Litter loss. Litter loss is estimated assuming a fixed life span for each biomass component. Needle life span is taken to be 5 years, and hence annual needle litter loss is estimated to be $20 \%$ of the total needle biomass present. Branch and root life spans are assumed to be 20 and 10 years, respectively, resulting in annual litter loss of $5 \%$ and $10 \%$ of component biomass present. Stems are harvested during thinning or at the end of the rotation, and therefore are not included in the yearly litter loss.

Again, the coefficients are only used as an indication of the magnitude of the processes. Large uncertainties concerning the actual values remain, especially with regard to root turnover, and further research in this area is needed. Ultimately, net yearly increments for each component $i$ (needles, branches, roots or stems) can be expressed as:

$P_{i}=\mathrm{DWC}\left(\mathrm{DC}_{i} \times \mathrm{GPP}-R_{i}\right)-L_{i}$

with $P_{i}=$ net yearly increment (ton dry wt. ha ${ }^{-1}$ ); DWC = dry weight conversion (ton dry wt. $\operatorname{ton}^{-1} \mathrm{CH}_{2} \mathrm{O}$ ); $\mathrm{DC}_{i}=$ distribution coefficient for assimilates; GPP $=$ gross primary productivity (ton $\left.\mathrm{CH}_{2} \mathrm{O} \mathrm{ha}^{-1} \mathrm{yr}^{-1}\right) ; R_{i}=$ component maintenance respiration (ton $\mathrm{CH}_{2} \mathrm{O} \mathrm{ha}{ }^{-1} \mathrm{yr}^{-1}$ ); $L_{i}=$ component litter loss (ton dry wt. ha ${ }^{-1} \mathrm{yr}^{-1}$ ).

Specific gravity. Stem increment is converted to $\mathrm{m}^{3}$ stemwood by dividing dry weight increment by specific gravity, for which a value of 0.47 ton dry wt. $\mathrm{m}^{-3}$ is used (Laming et al., 1978).

Applying the coefficients and parameter values mentioned above gives a potential production rate for Douglas fir in The Netherlands of 20$25 \mathrm{~m}^{3}$ stemwood per hectare per year, which is in agreement with measured maximum current annual increment rates in field plots on the best sites available (La Bastide and Faber, 1972).

\subsection{Actual productivity}

Deviations between actual productivity and the estimated theoretical maximum can be caused by incomplete canopy closure, site effects such as limiting water and/or nutrient availability, and pests, diseases and weeds. First, the degree of canopy closure and the way this is incorporated in the model will be discussed. Then site effects expressed as a site reduction factor will be introduced. The influence of pests, diseases and weeds will not be considered here. Also, the effects of possible harmful abiotic factors such as $\mathrm{SO}_{2}$ and $\mathrm{NO}_{x}$ are not taken into account.

Degree of canopy closure. Radiation is intercepted by stems and branches as well as needles. In estimating gross photosynthesis, only needle surface area must be considered, as branch and stem surface do not contribute to photosynthesis. In the model it is assumed that needle surfaces mask branch and stem surfaces and that the interception of radiation for photosynthetic 
processes, can be simply estimated using an exponential light extinction model as proposed by Monsi and Saeki (1953):

$I=I_{0} \mathrm{e}^{-k \times \text { LAI }}$

with $I=$ amount of radiation at the forest floor $\left(\mathrm{W} \mathrm{m}^{-2}\right) ; I_{0}=$ amount of radiation immediately above the canopy $\left(\mathrm{W} \mathrm{m}^{-2}\right) ; k=$ extinction coefficient; LAI = leaf area index (ha foliage per ha soil surface); $\mathrm{e}=$ base of natural logarithm. Leaf area index is calculated from simulated needle biomass using a specific leaf area of 0.85 ha ton $^{-1}$ (Del Rio and Berg, 1979). In the model, the extinction coefficient $k$ is set to decrease linearly with time from 0.8 at stand establishment to 0.4 at an age of 100 years (Kinerson and Fritschen, 1971; Kira, 1975). The decrease of $k$ with increasing tree age accounts for increasing transmittance of the tree crowns due to greater distances in the crown mantel of large, full-grown trees between the branches carrying most of the needles. This results in small gaps within the crown projection area (Kira et al., 1969).

The degree of canopy closure must be estimated in the horizontal as well as in the vertical plane in the canopy. Apart from the vertical closure treated above, horizontal closure of the canopy has to be estimated in relation to incident radiation in order to account for large gaps between the individual tree crowns. The degree of horizontal canopy closure depends on stand density, spatial distribution, dimensions of the tree crowns, and solar elevation (Satterlund, 1983; Oker-Blom and Kellomäki, 1983). As the dimensions of the tree crowns change with individual tree growth, and as stand density and spatial distribution of the crowns are influenced by thinning management, it is not possible to deal with horizontal canopy closure using some fixed function of time. In the model, the degree of closure is approximated by assuming cone-shaped crowns (Fig. 3). For each tree, the shaded area $\left(\mathrm{CC}_{i}\right)$ can now be calculated as a function of crown radius at the base of the crown or perpendicular crown projection area, crown length and the angle of incoming solar radiation:

$\mathrm{CC}_{i}=a \times \mathrm{CP}_{i}$

with $\mathrm{CC}_{i}=$ effective crown projection with regard to incident radiation (Fig. 3); $\mathrm{CP}_{i}=$ perpendicular crown projection area; $a=$ ratio of effective to perpendicular crown projection area, estimated as a function of the ratio $h / r$ and the angle $\beta$ of incoming radiation (see Monteith, 1973), $h$ and $r$ representing crown length and crown radius, respectively. Crown radius is calculated as a function of stem diameter at breast height using data from Schneider and Kreysa (1981). Crown length $(h)$ is estimated from crown radius and the ratio crown length/crown radius $(h / r)$, which is assumed to vary from 4 at an age of 10 , to 1 at an age of 100 years. This must be viewed as a gross approximation of the dimensions of the effective green needle-bearing crown. A mean value of $30^{\circ}$ has been taken for the solar elevation. 


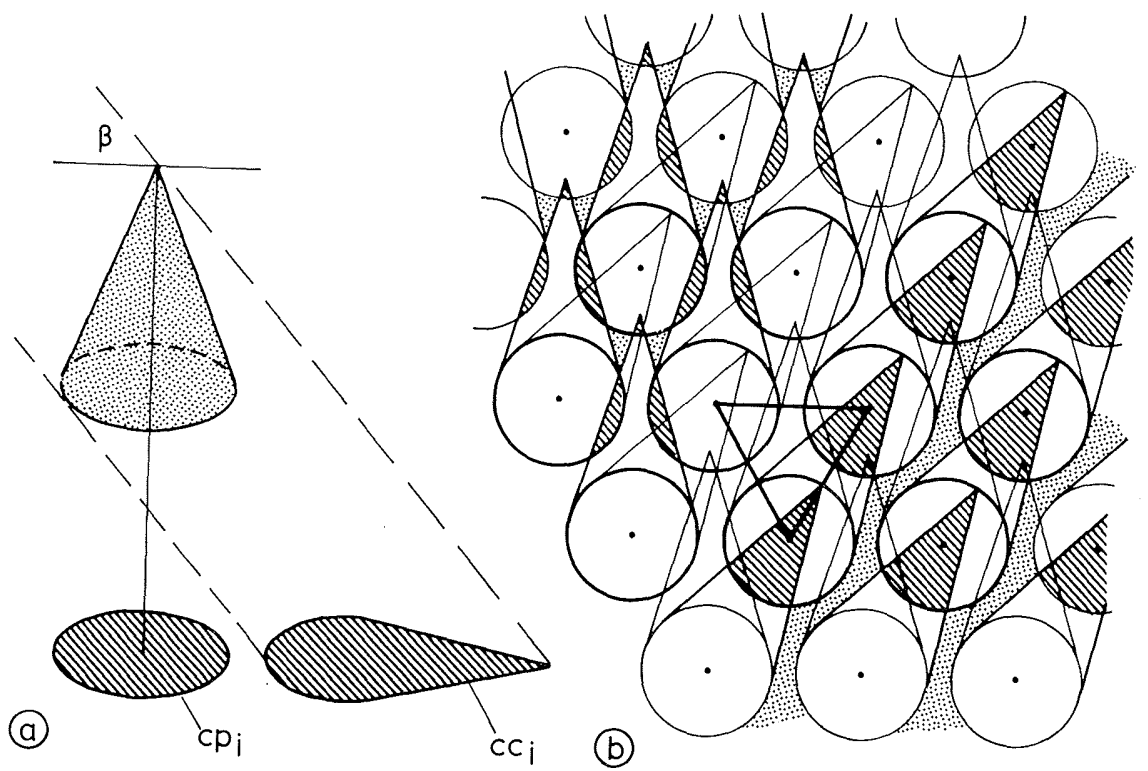

Fig. 3. Estimation of crown projection area with regard to incoming radiation, assuming cone-shaped crown and average angle $\beta$ for solar elevation. Effective crown projection area with regard to interception of incoming radiation (area $\mathrm{CC}_{i}$ see Fig. a) is estimated from perpendicular crown projection area $\left(\mathrm{CP}_{i}\right)$ calculated from diameter at crown base, crown height, and angle $\beta$. The degree of mutual shading is estimated as a function of total stand perpendicular crown projection area (sum of areas $\mathrm{CP}_{i}$ in Fig. a) and the ratio of crown height to crown radius, under the assumption of identical trees in an equilateral triangle spacing. In this situation, mutual shading is calculated for two extreme sun positions, shown in the upper left hand corner and the lower right hand corner of Fig. b, respectively. Total mutual shading is taken as the mean of the shading in both positions. See Fig. 4 for results.

Mutual shading of trees in a stand has to be taken into account if crown closure is to be estimated on the basis of individual tree shadows. Total canopy closure can be expressed as:

$$
\begin{aligned}
\mathrm{CC} & =\sum_{i=1}^{N}\left(\mathrm{CC}_{i}\right)-b \\
& =a \sum_{i=1}^{N}\left(\mathrm{CP}_{i}\right)-b
\end{aligned}
$$

with $\mathrm{CC}=$ total canopy closure $\left(\mathrm{haha}^{-1}\right) ; N=$ total number of trees per hectare $\left(\mathrm{ha}^{-1}\right) ; b=$ reduction due to mutual shading: $b=\mathrm{f}(\mathrm{CP}, h / r)$. The degree of mutual shading is estimated using a simple geometrical abstraction of the canopy by calculating mutual shading of identical cone-shaped crowns in an equilateral triangle spacing (Fig. 3b). It appears that the amount of shading can be expressed as a simple descriptive function of the ratio crown length/crown radius and total perpendicular crown projection 


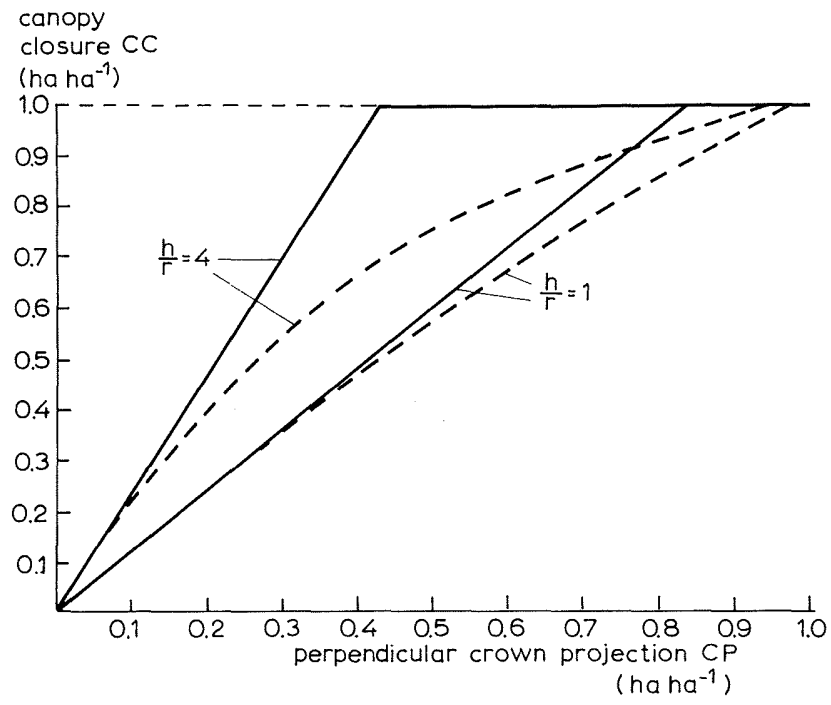

Fig. 4. Effective canopy closure as a function of perpendicular crown projection area and the ratio crown length to crown radius. Results from estimation procedure as depicted in Fig. 3. On the horizontal axis perpendicular crown projection area, or the sum of the areas $\mathrm{CP}_{i}$ in Fig. 3, for the whole stand is given. Solid lines represent total shaded area without any correction for mutual shading (sum of the areas $\mathrm{CC}_{i}$ in Fig. 3 ). The slope of the solid lines when canopy closure has not yet reached its maximum value, represents the ratio between the surfaces $\mathrm{CC}_{i}$ and $\mathrm{CP}_{i}$ in Fig. 3a, which can be characterized by the ratio crown height/crown radius. At the left in the figure, this ratio equals 4 (long narrow crowns), at the right the ratio is 1 (wide shallow crowns). The dotted lines show the influence of the correction for mutual shading (Fig. $3 \mathrm{~b}$ ) on total canopy closure. In the case of a high crown length/crown radius ratio, mutual shading is much higher for the same perpendicular crown projection area as compared to a low ratio. Incidentally, competition in the stand can be seen to start early (competition is assumed to start as soon as mutual shading occurs): at canopy closure of about 0.2 in the case of a high length/radius ratio, at about 0.3 in the case of a low ratio.

area (CP) in haha ${ }^{-1}$. Leaf area index (LAI) is expressed with regards to the closed canopy fraction only (using CC from eq. 4), and is calculated as total needle surface per ha divided by CC. The result of this calculation of effective canopy closure by adding individual tree shadows and subtracting mutual shading, is shown in Fig. 4 (see also Satterlund, 1983, for a more elaborate treatment). The procedure is valid only in rather homogeneous even-aged stands with optimal or near-optimal spacing (optimal as far as interception of incident radiation is concerned). Heavy thinning may lead to considerable (temporary) decrease in horizontal crown projection area, and hence to a decrease in canopy closure. No thinning effects on spacing of the trees, as, for example, non-optimal spacing shortly after thinning, are taken into account. In fact, the trees in the model can be regarded as being continuously moving around, so that the stand as a whole intercepts as much radiation as possible. The fraction of total incoming radiation intercepted by the whole stand $\left(F_{\text {int }}\right)$ is calculated by multiplying canopy 
closure by the fraction of radiation intercepted within the individual tree crowns, calculated from the extinction equation:

$F_{\text {int }}=\mathrm{CC}\left(1-\mathrm{e}^{-k \times \mathrm{LAI}}\right)$

Site effects. In conventional forest growth and yield research, site quality is usually evaluated based on the total stand height development. Stand height appears to be strongly correlated with production capacity of the site and this empirical correlation has been used extensively by foresters (see Tesch, 1981, for an overview). Total stand height is most conveniently characterized by stand dominant height which is defined as the mean height of the ten highest trees per hectare. Dominant height is preferred as a measure of stand height because it is less susceptible to changes due to thinning as the largest trees usually are not removed. Dominant height development with age follows an S-shaped curve, and the asymptotic level at greater ages can be used to classify site quality. The height-versus-age curve can be described with the Chapman-Richards curve (Pienaar and Turnbull, 1973; Avery and Burkhart, 1983):

$H_{\text {dom }}=S\left(1-\mathrm{e}^{-c t}\right)^{d}$

with $H_{\text {dom }}=$ dominant height $(\mathrm{m}) ; S=$ asymptote, referred to as absolute site index $(\mathrm{m}) ; t=$ age (yr); e = base of natural logarithm; $c, d=$ regression coefficients. For Douglar fir in The Netherlands, La Bastide and Faber (1972) give values for the coefficients $c$ and $d$ of 0.034 and 1.421 respectively, with the $S$ value varying between $45 \mathrm{~m}$ on the best sites available to $25 \mathrm{~m}$ on sites of poor productivity. Using equation (7) the value for $S$ can be estimated from measurement of $H_{\mathrm{dom}}$. In the model this site index is used to quantify the deviation of actual primary production from the potential level by applying a reduction factor for gross photosynthesis, which is linearly related to the value for $S$ of a given site:

$F_{\mathrm{s}}=f+g S$

with $F_{\mathrm{s}}=$ reduction factor for gross photosynthesis; $f, g=$ coefficients based on the yield tables for Douglas fir (La Bastide and Faber, 1972). In the model the values used for $f$ and $g$ are 0.360 and 0.0145 , respectively. The coefficients are based on the maximum values of annual stem volume increment for a given site index in the yield tables.

This procedure, deducing a site index-dependent reduction factor from the current yield tables in order to account for lower gross primary production under non-optimal conditions, has the advantage of coupling the ecophysiological approach to the usual yield tables in a straightforward way. This means that results from the more fundamental approach to forest productivity can be related directly to practical aspects of forest growth and yield. On the other hand, the procedure tends to cover up essential processes of water and nutrient supply. This was done in this paper to 
allow evaluation of the possibility of applying an ecophysiological approach to forest productivity, without having to go into this detail. The actual gross productivity in a given situation can be expressed as:

$\mathrm{GPP}_{\text {act }}=F_{\text {int }} F_{\mathrm{s}} \times \mathrm{GPP}_{\text {pot }}$

Substitution of GPP ${ }_{\text {act }}$ for GPP in equation (1) gives the actual net increment for needles, branches, stems and roots.

\subsection{Stand structure}

The representation of forest stand structure in the simulation model is chosen in such a way that it is compatible with conventional growth and yield research in forestry. This was done to be able to compare simulation outcome with empirical growth and yield models, and to use measurements from existing permanent field plots. Therefore, considerable attention is given to the stem diameter at breast height (DBH) because this is the main quantity measured in the field. The simulated volume increment $\left(\mathrm{m}^{3} \mathrm{ha}^{-1} \mathrm{yr}^{-1}\right)$ is distributed over the trees which make up the stand. The diameter increment is derived for each tree from this individual tree volume increment by using a tree volume equation. In conventional growth and yield research, measurements from permanent field plots usually consist of $\mathrm{DBH}$ values of all trees on the plot, a sample of tree height measurements with the corresponding DBH over the range of diameters measured in the plot, and an estimate of dominant height $\left(H_{\text {dom }}\right)$ as a characteristic of stand height. The sample of tree height-DBH measurements is used to estimate tree height of each individual tree from the regression equation (Curtis, 1967):

$H_{i}=h+m \ln \left(\mathrm{DBH}_{i}\right)$

with $H_{i}=$ tree height of tree $i(\mathrm{~m}) ; \mathrm{DBH}_{i}=$ diameter at breast height of tree $i(\mathrm{~cm}) ; \ln =$ natural logarithm; $h, m=$ regression coefficients, estimated from the measured sample. This means that the measurements at a given age provide a diameter frequency distribution, an empirical diameter-height relationship, and an estimate of dominant height.

Individual tree stem volume is calculated from diameter and height, using the Schumacher and Hall (1933) volume equation:

$V_{i}=n \times \mathrm{DBH}_{i}^{p} \times H_{i}^{q}$

with $V_{i}=$ stem volume of tree $i\left(\mathrm{~m}^{3}\right) ; \mathrm{DBH}_{i}=$ diameter at breast height of tree $i(\mathrm{~cm}) ; H_{i}=$ height of tree $i(\mathrm{~m}) ; n, p, q=$ regression coefficients, based on stem section measurement of felled trees; for $n, p$ and $q$, values of $0.593 \times 10^{-4}, 1.783$ and 1.058, respectively, are used (P.J. Faber, personal communication, 1982). The diameter frequency distribution in the model is characterized by an array of 20 diameters corresponding to the medians 
of 20 percentile classes (each containing $5 \%$ of the total number of trees). At initialization of the simulation of an existing permanent field plot, the percentile classes are extrapolated from the measured cumulative DBH frequency distribution (see Alder, 1979). Together with the weight per hectare of the biomass components, the array of diameters simulated can be regarded as the central state variables in the model. To simulate a hypothetical stand the array of diameters is generated using the integral of the 3-parameter Weibull distribution function (Bailey and Dell, 1973).

Distribution of stand increment over the percentile classes, and within these classes over the individual trees, is done according to a tree or class characteristic which is assumed to represent the part that the tree or class takes in total gross production. This is a simple and effective procedure to account for competition within the stand. This simulation of competition is treated in detail in a forthcoming publication (Mohren et al., in prep.); thus it is only briefly mentioned here. Basically, if competition for light is most important, the amount of photosynthetically active radiation that an individual tree receives relative to the total amount intercepted by the stand will be a good measure of the part that the tree takes in total gross productivity. As a first approximation, individual tree total needle biomass can be used as index for total radiation intercepted. Due to the fixed distribution coefficients for assimilates used in the model, needle biomass per tree is proportional to individual tree stem weight which means that individual tree stemwood volume (equation 10) can be used for competition index.

The calculated volume increment per tree is added to the existing volume and, solving the equations (9) and (10) for each percentile class, a new array of diameters can be calculated. This new diameter frequency distribution is then used to estimate the degree of canopy closure at the beginning of the next time step. Stand height development is characterized in the model by dominant height development, either by using measured dominant height development as input (in the case of an actual stand simulation), or by calculating $H_{\text {dom }}$ from a given value for $S$ (with hypothetical stand simulation). The coefficients needed in equation (9) to estimate individual tree height from tree diameter are either deduced from dominant height development in the case of simulation of a hypothetical stand, or are based upon successive field measurements in the case of actual stand simulation.

\subsection{Thinning management}

Thinning management in forestry tries to create favourable conditions for stand development during the rotation. This is done by deliberately manipulating stand structure in order to leave the trees which will make up the stand at harvest time under favourable growing conditions. Trees are removed to make space for crown development of the remaining ones, which results in larger production per tree for the remaining trees. Dif- 
ferent types of thinning can be defined, based on the distribution in the field of the trees to be removed (e.g. row-thinning) or the dimensions of the trees to be removed compared to the dimensions of the remaining trees (e.g. thinning from below or from above), and on the intensity of thinning expressed in number of trees or total amount of wood volume to be removed (heavy compared to light or moderate thinning). In the present version of the model, thinning can be executed by calling a thinning algorithm. The trees to be thinned have to be specified in a diameter frequency table which is used as input. This means that virtually all types of thinning can be simulated. The thinning specification can be based on actual thinning management, as with simulation of permanent field plots, or can be based on simulation results at the time of thinning in the case of a hypothetical stand simulation.

When the thinning algorithm is called, a number of the trees in the stand, specified by their diameters only, are removed, together with an equivalent amount of needle, branch and root biomass. Immediately afterwards, a new array of diameters is calculated to represent the remaining stand. As a result of this thinning procedure, stem volume and total stem dry weight are also reduced.

\section{SIMULATION RESULTS AND MODEL BEHAVIOUR}

Model performance will be evaluated in two distinct situations: simulation of a hypothetical stand and of an actual stand. The latter can be used to compare model outcome with measurements from existing permanent field plots, thus providing an indication of the validity of the model. At present, the model cannot be validated rigorously, as the coefficients for distribution of assimilates and maintenance respiration are based on literature values, and are used to fit the model to the data by adjustment of the coefficients within the range reported in the literature. This means that the model is, at least partly, calibrated against the field plots. Simulation of a hypothetical stand is used to gain understanding of the relation between the different components of the gross primary productivity, and the influence of thinning on this.

In this way, distribution of gross productivity over net increment, respiration and loss, together with possible thinning influence on net increment during stand development, leads to insight into the possibilities available for increasing or manipulating total yield.

\subsection{Simulation of gross productivity, respiration and net increment}

The hypothetical stand simulation is initialized by means of the current yield tables for The Netherlands (La Bastide and Faber, 1972). The simulation performed for site index equal to $41.5 \mathrm{~m}(S)$, is nearly optimal. Initial number of trees per ha is 2000 . In the case of thinning, the stem reduction 


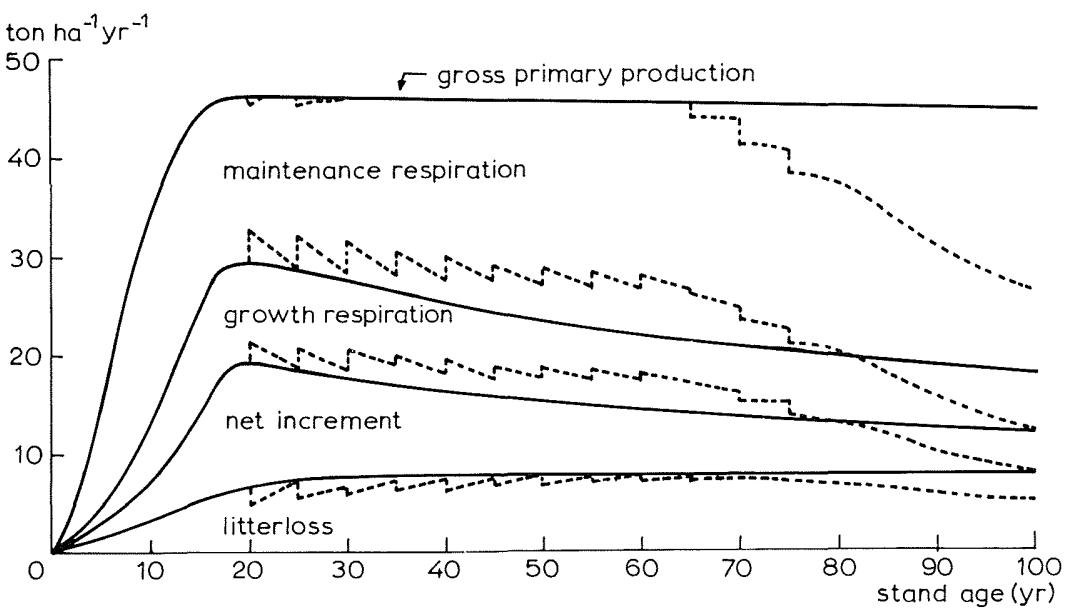

Fig. 5. Simulated trends in gross primary production, respiration, net increment and litter loss during stand development. Solid lines: simulation without thinning. Dotted lines: simulation with thinning according to yield tables (La Bastide and Faber, 1972). Trends shown for near optimal site index $(S=41.5)$, starting with an amount of 2000 trees per ha which is thinned to 230 trees per ha at age 75 . The first three thinnings (at ages 20,25 and 30 ) slightly reduce gross production by reducing canopy closure. Between age 30 and age 65 , the canopy remains completely closed and thinning results in increased net increment due to decreased maintenance respiration. After age 65, the canopy is permanently opened as crown expansion after thinning is unable to reach complete closure again.

is carried out according to the yield tables, which means thinning at 5-year intervals from age 20 until age 75 . The total number of stems is then reduced to 230 per ha. The simulated distribution of gross productivity over net. increment, litter loss and maintenance and growth respiration, is shown in Fig. 5. Gross primary productivity during stand development is assumed to increase exponentially after stand establishment. As soon as mutual shading of neighbouring trees occurs (see also Fig. 4), competition starts, and the increase in gross productivity becomes less. Immediately before crown closure, mutual shading is considerable and the maximum gross productivity level is approached slowly.

In the absence of thinning, gross productivity (GPP) equals 46 ton $\mathrm{CH}_{2} \mathrm{O}$ $\mathrm{ha}^{-1} \mathrm{yr}^{-1}$ at age 20, and gradually decreases somewhat to a value of 45 ton $\mathrm{CH}_{2} \mathrm{O} \mathrm{ha}^{-1} \mathrm{yr}^{-1}$ at age 80 . Repeated thinnings as indicated by the yield tables may, in combination with decreasing light interception within the tree crowns, cause a considerable decrease of gross productivity. This effect, which becomes clear at higher stand ages, is represented by the dotted lines in Fig. 5. Simulation of thinning according to the yield tables results in a decrease of GPP from 46 ton $\mathrm{CH}_{2} \mathrm{O} \mathrm{ha} \mathrm{hr}^{-1} \mathrm{yr}^{-1}$ at age 20 (canopy closure) to 36 ton $\mathrm{CH}_{2} \mathrm{O} \mathrm{ha}^{-1} \mathrm{yr}^{-1}$ at age 80 . If, with thinning, the canopy remains practically closed, the result is an increase in net increment shortly after thinning because of lower living biomass and hence less maintenance respira- 


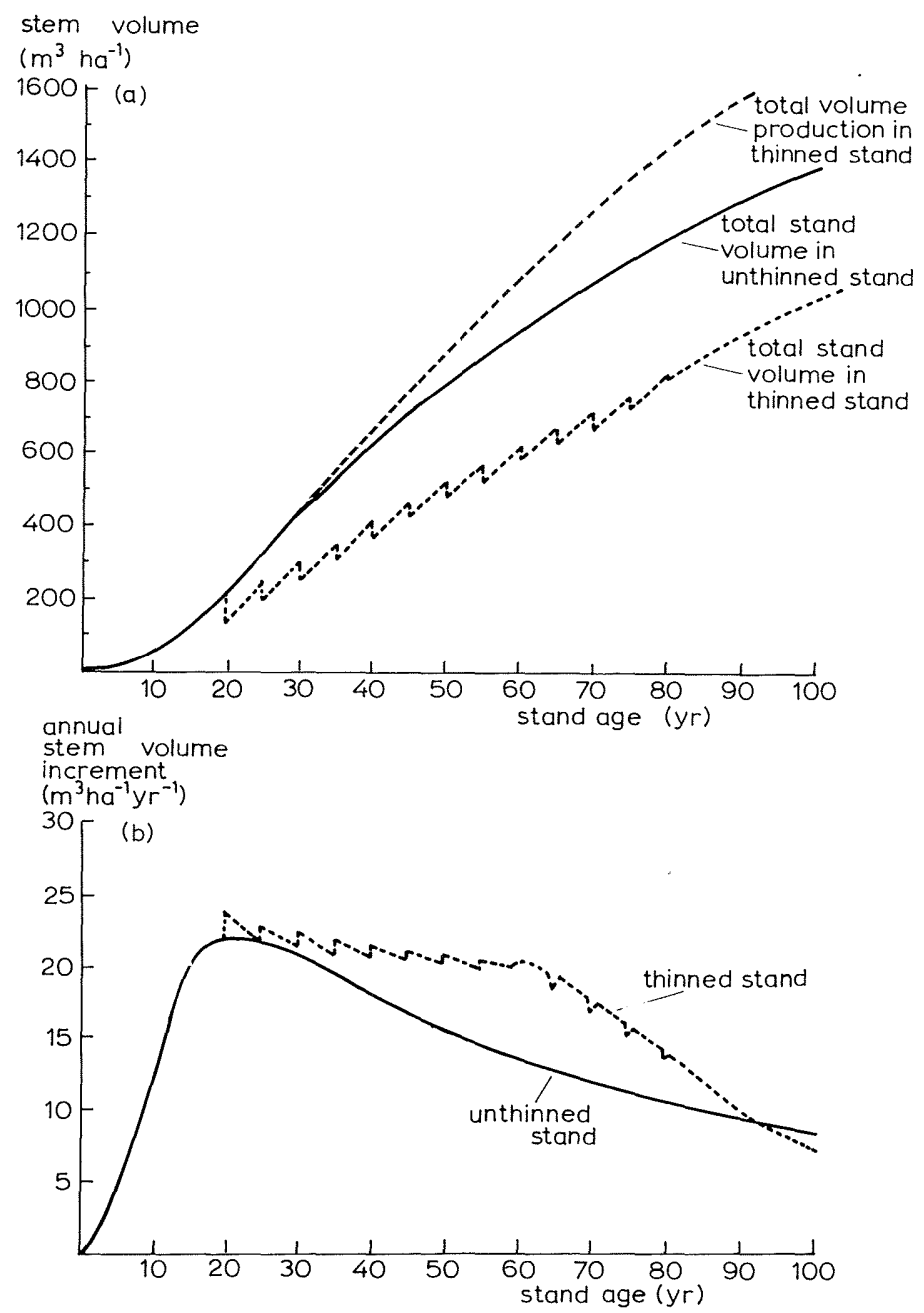

Fig. 6. (a) Simulated total stand volume development in thinned (dotted lines) and unthinned (solid line) situation. Simulation results corresponding to Fig. 5.

(b) Simulated current annual volume increment for the thinned (dotted line) and unthinned situation (solid line).

Figures $a$ and $b$ show the simulated influence of thinning on annual stem volume increment. Absence of thinning results in lower net volume increment. At the end of the stand development, increment for the thinned stand becomes less than increment in the unthinned situation due to decreasing canopy closure.

tion immediately following thinning. This can be seen clearly between ages 20 and 60 in Fig. 5. From this it can be concluded that in general thinning increases total yield as long as the canopy is kept closed.

In the model, total maintenance respiration increases somewhat with increasing total biomass, but not proportional to it. Accumulation of biomass during stand development is caused largely by accumulation of dead heart- 
wood in the stems which does not need any maintenance respiration (see 2.2 ). Due to the higher number of trees per ha in the unthinned situation, total amount of sapwood is greater than in the thinned situation, which results in a larger part of gross productivity being used in maintenance respiration in the unthinned situation. The model indicates that complete canopy closure, in combination with low living biomass per hectare, as in case of the thinned stand, leads to more efficient production than in the unthinned situation with higher living biomass per ha.

Total wood volume production and simulated annual stem volume increment corresponding to the situations depicted in Fig. 5 are shown in Fig. 6. This figure shows that current annual stem volume increment is higher in the thinned situation than in the simulation without thinning. With thinning, the increment decreases from about $24 \mathrm{~m}^{3} \mathrm{ha}^{-1} \mathrm{yr}^{-1}$ at an age of 20 immediately after thinning, to a value of $13 \mathrm{~m}^{3} \mathrm{ha}^{-1} \mathrm{yr}^{-1}$ at an age of 80 . Without thinning, the stem volume increment decreases from 22 $\mathrm{m}^{3} \mathrm{ha}^{-1} \mathrm{yr}^{-1}$ at age 20 to $10 \mathrm{~m}^{3} \mathrm{ha}^{-1} \mathrm{yr}^{-1}$ at age 80 . This means that in spite of incomplete canopy closure (at age $80, F_{\text {int }}$ equals 0.7 when thinned and 0.9 when unthinned) annual stem volume increment is higher in the thinned stand. As a consequence, total volume production in the thinned situation over the period of stand development exceeds total volume production in the unthinned stand by about $300 \mathrm{~m}^{3} \mathrm{ha}^{-1}$ or approximately $25 \%$.

In addition to the increase in total stem volume, the trees in the thinned stand have much larger diameters at breast height due to the smaller number of trees per ha which take part in the growth. At age 20, both thinned and unthinned stands have an average diameter at breast height of around $14 \mathrm{~cm}$. At age 80 , the trees in the unthinned stand (2000 trees per ha) have an average diameter of $23 \mathrm{~cm}$ whereas the trees in the thinned stand (with only 230 trees per ha left out of 2000) have an average diameter of $59 \mathrm{~cm}$.

In considering these simulation results it must be kept in mind that mortality effects are not incorporated in the model. In the unthinned stand, with 2000 trees per ha, mortality acts as natural or self-thinning, thus reducing the number of stems per ha. Due to mortality, the difference between the simulation results in the thinned and unthinned situation are likely to become less pronounced.

\subsection{Simulation of field plots}

The field plots used for comparison of simulated and actual growth and yield were measured for periods of 35 years (1923 until 1958, plot no. D5), 42 years (1925 until 1967, plot no. D9) and 52 years (1923 until 1975, plot no. D12) and are located in the centre of The Netherlands. The measured series are part of the data base of the Growth and Yield Department of the Forestry Research Institute 'De Dorschkamp' at Wageningen, The Netherlands. 

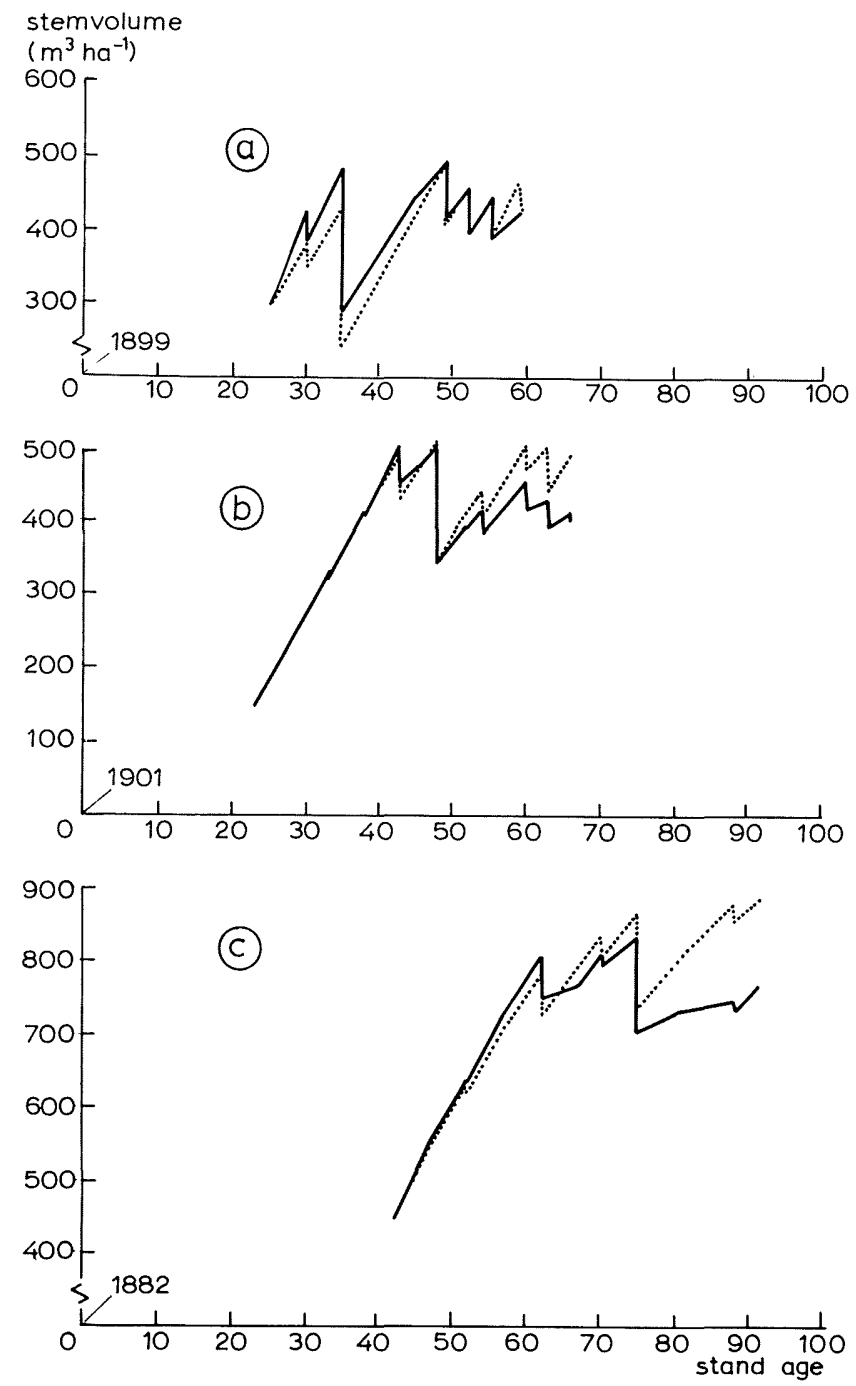

Fig. 7. Actual (solid line) and simulated (dotted line) stem volume development for the permanent field plots mentioned in the text (D5: a; D9: b; D12: c). Site indices of the three plots correspond to $33-36$ for $\mathrm{D} 5,33$ for $\mathrm{D} 9$, and $41-44$ for $\mathrm{D} 12$. In all three cases it can be seen that the model tends to underestimate stem volume at the beginning of the simulation period, followed by an overestimation at the end.

All three stands have been thinned according to normal forestry practice during the measurement period. In general, this means moderate thinning from below. Dominant height development during the measurement period is used to calculate the site index of the stands. Subsequently, site index $(S)$ has been used to calculate the reduction factor for gross primary production (eq. 7). Average reduction factors used are $0.86,0.84$ and 0.98 for D5, 
D9 and D12, respectively. The field plot D12 can be considered to be a near optimal site for Douglas fir in The Netherlands. Figure 7 shows the results of the simulations together with the measurements of the three plots. In comparing the results for each of the plots, it must be kept in mind that the total volume per ha of plot D12 is about twice as much as the total volume of D5 or D9.

As mentioned before, the simulation of actual stand growth is initialized by using actual stand structure at the first time of measurement as input. Hence both lines, simulated and measured, start from the same situation. Thinning is simulated by using the thinning data from the field plots as input in the model: trees removed in the field plots by thinning are also removed in the model. From Fig. 7a, b and $c$ it can be seen that the model slightly underestimates total volume growth at the beginning of the simulation, and afterwards, at higher stand ages, tends to overestimate volume growth considerably.

Overestimation of total volume can be caused by a sudden drop in stem volume increment in the field plots during some years. After some time the increment increases again, but as the model uses an average production level and does not take into account temporary decreases in the field, this leads to underestimation before, and overestimation directly after the productivity drop. In addition to this, an effect of water shortage on the relationship between height growth and total dry matter growth is possible: height growth takes place early in the growing season (Mitscherlich, 1978) whereas a large proportion of total dry weight increment takes place in the middle of the growing season. This means that the influence of water shortage on increment later in the season will not be reflected in height growth. Hence it is possible that the empirical reduction for site effects is too small and so results in overestimation of increment. In considering the fit for the model, it must be remembered that due to the calibration procedure for the distribution and respiration coefficients, the simulation results are not independent of the measurement series.

Apart from the above reasons for overestimation of net yearly increment in the model, some other possible explanations for declining increment, which are not yet incorporated in the model, should be mentioned.

The extinction coefficient of photosynthetically active radiation is assumed to decrease from 0.8 at stand establishment to 0.4 at age 100 , with the trees in some kind of 'optimal' arrangement with regard to interception of incoming radiation per hectare. In the case of small crown lengths and considerable clustering of needles around branches which are far apart in the crown mantle, light extinction might still be overestimated when an extinction coefficient of 0.4 is used (see, for example, values quoted by Jarvis et al., 1976). With regard to spacing (horizontal canopy closure), thinning at high stand ages may lead to non-optimal spacing, which cannot be compensated by crown expansion of the remaining trees, because crown expansion has reached its maximum value. In that case, the model over- 
estimates the fraction of radiation intercepted by the stand, by overestimation of CC (eq. 4).

Gradual changes in the distribution of assimilates over the various parts of the tree during stand development may lead to a smaller proportion allocated to the stems at increasing stand age. In the model, fixed distribution coefficients are used which, in that case, would lead to overestimation of the proportion of assimilates allocated to the stems. Allocation of assimilates might be changed, for example, in association with increasing flowering and seed production at higher ages.

Due to accumulation of organic matter, dead as well as alive, during stand development, an increasing amount of nutrients is immobilized in this biomass. This might allow decomposition processes to determine the maximurn attainable growth rate, and the stand, while retaining its nutrients, might create its own deficiency (Miller, 1979).

Finally, increasing tree height during stand development causes longer xylem pathways for transpiration. As a consequence of this, total xylem resistance to water flow increases as the trees grow bigger. This may result in earlier stomatal closure during the day, thus limiting transpiration and $\mathrm{CO}_{2}$ assimilation (see, for example, Hellkvist et al., 1974).

\section{CONCLUDING REMARKS}

Using the approach presented, it is possible to study primary production and wood yield in even-aged forests without too much detail on stand structure and complexity. Simulation of actual stand behaviour and of hypothetical stand dynamics shows the possibility of coupling an ecophysiologically based simulation model with conventional growth and yield research in a straightforward way. Care must be taken, however, in using diameter at breast height as the central variable in an ecophysiological model; $\mathrm{DBH}$ is not a primary quantity in dry matter production. To make the model output compatible with empirical growth and yield models it is necessary to simulate wood volume from total biomass dry weight, but the model would reduce to a largely empirical model if growth were assessed as diameter growth only (see, for example, Alder and Schneider, 1979). On the other hand, the advantage of using a top-down approach as presented in this study is that stand structure can be assessed in a general way, whereas use of diameter increment as a basic growth function in a bottom-up approach needs detailed information on individual tree environment in order to estimate it with sufficient accuracy.

In estimating primary productivity at a canopy level in a deterministic way, using ecophysiological relationships, it is necessary to handle all parts of the model with the same degree of sophistication. From this point of view, the use of an empirical site index based on dominant height is a major drawback of the model. It must be stressed that the site classification system used in forestry is also in practice not too useful in explaining actual 
production. More research in this field is needed (Reed, 1980) and a deterministic modelling approach as presented here is a valuable tool (see also Linder, 1981). In the present model, the use of dominant height to characterize the overall production level has as a consequence that the production level cannot become less when $H_{\text {dom }}$ approaches the value of $S$ at greater ages because tree height does not decrease. This means that explanations for decreased growth at greater ages cannot be accounted for in a model based entirely on site index. At the moment, the preliminary model used here is being revised and elaborated by substituting the strongly empirical and descriptive parts in the model by more functional relationships, especially concerning the site index reduction factor used.

\section{REFERENCES}

Alder, D., 1979. A distance-independent tree model for exotic conifer plantations in East Africa. For. Sci, , 25: 59-71.

Alder, D. and Schneider, T.W., 1979. A stand growth model as a tool in studying management options for MAB-rainforest ecosystem projects and for temperate forests. In: S. Adisoemarto and E.F. Brünig (Editors), Transactions of the Second International MAB-IUFRO Workshop on Tropical Rainforest Ecosystems Research, 21-25 October 1978, Jakarta. Spec. Rep. 2, Chair of World Forestry, Hamburg-Reinbek, pp. 128-165.

Avery, T.E. and Burkhart, H.E., 1983. Forest Measurements (3rd revised Edition). McGraw-Hill, New York, NY, $331 \mathrm{pp}$.

Bailey, R.L. and Dell, T.R., 1973. Quantifying diameter distributions with the Weibull function. For. Sci., 19: 97-104.

Curtis, R.O., 1967. Height-diameter and height-diameter-age equations for second growth Douglas-fir. For. Sci., 13: 365-375.

Del Rio, E. and Berg, A., 1979. Specific leaf area of Douglas-fir reproduction as affected by light and needle age. For Sci., 25: 183-186.

De Wit, C.T., 1965. Photosynthesis of leaf canopies. Agric. Res. Rep. 663, Pudoc, Wageningen, $57 \mathrm{pp}$.

De Wit, C.T. et al., 1978. Simulation of assimilation, respiration and transpiration of crops. Simulation Monogr., Pudoc, Wageningen, $141 \mathrm{pp}$.

Goudriaan, J., 1979. A family of saturation type curves, especially in relation to photosynthesis. Ann. Bot., 43: 783-785.

Goudriaan, J. and Van Laar, H.H., 1978. Calculation of daily totals of the gross $\mathrm{CO}_{2}$ assimilation of leaf canopies. Neth. J. Agric. Sci., 26: 373-382.

Hellkvist, J., Richards, G.P. and Jarvis, P.G., 1974. Vertical gradients of water potential in Sitka spruce trees measured with the pressure chamber. J. Appl. Ecol., 11: 637667.

IBM, 1975. Continuous System Modelling Program III (CSMP III), Program Reference Manual. SH19-7001-3, Tech. Publ. Dep. IBM, White Plains, N.Y. U.S.A., 206 pp.

Jarvis, P.G., James, G.B. and Landsberg, J.J., 1976. Coniferous forest. In: J.L. Monteith (Editor), Vegetation and Atmosphere. Vol. 2, Case Studies. Academic Press, London, pp. $171-239$.

Kinerson, R.S. and Fritschen, L.J., 1971. Modelling a coniferous forest canopy. Agric. Meteorol., 8: 439-445.

Kira, T., 1975. Primary production of forests. In: J.P. Cooper (Editor), Photosynthesis and Productivity in Different Environments. Cambridge University Press, Cambridge, pp. $5-40$. 
Kira, T. and Shidei, T., 1967. Primary production and turnover of organic matter in different forest ecosystems of the Western Pacific. Jpn. J. Ecol., 17: 70-87.

Kira, T., Shinozaki, K. and Hozumi, K., 1969. Structure of forest canopies as related to their primary productivity. Plant Cell Physiol., 10: 129-142.

La Bastide, J.G.A. and Faber, P.J., 1972. Revised yield tables for six tree species in The Netherlands. Uitvoerig Versl, 11(1), Forestry Research Institute 'De Dorschkamp', Wageningen, $64+36 \mathrm{pp}$.

Laming, P.B., Rijsdijk, J.F. and Verwijs, J.C., 1978. Houtsoorten. Informatie voor de praktijk. Houtinstituut TNO, Delft, $390 \mathrm{pp}$.

Larcher, W., 1980. Physiological Plant Ecology (2nd revised Edition). Springer Verlag, Berlin/Heidelberg/New York, 303 pp.

Linder, S. (Editor), 1981. Understanding and predicting tree growth. Stud. For. Suec., $160,87 \mathrm{pp}$.

Miller, H.G., 1979. The nutrient budgets of even-aged forests. In: E.D. Ford, D.C. Malcolm and J. Atterson (Editors), The Ecology of Even-Aged Forest Plantations. Institute of Terrestrial Ecology, Cambridge, pp. 221-255.

Mitscherlich, G., 1978. Wald, Wachstum und Bestand. Vol, 1, Form und Wachstum von Baum und Bestand (2nd revised Edition). Sauerländers Verlag, Frankfurt am Main, $144 \mathrm{pp}$.

Mohren, G.M.J., Van Gerwen, C.P. and Spitters, C.J.T., in prep. Simulation of competition in even-aged stands of Douglas-fir.

Mфller, C.M., 1945. Untersuchungen über Laubmenge, Stoffverlust und Stoffproduktion des Waldes. Forstl. Fors $\phi$ gsvaes. Dan. 17 (1): 1-287.

Monsi, M. and Saeki, T., 1953. Über den Lichtfaktor in den Pflanzengesellschaften und seine Bedeutung für die Stoffproduktion. Jpn. J. Bot., 14: 22-52.

Monteith, J.L., 1973. Principles of Environmental Physics. Edward Arnold, London, $241 \mathrm{pp}$.

Munro, D.D., 1974. Forest growth models - a prognosis. In: J. Fries (Editor), Growth Models for Tree and Stand Simulation. Proc. Meet. IUFRO Working Party S4-01-4. Department of Forest Yield Research, Royal Colleg of Forestry, Sweden, pp. 7-21.

Oker-Blom, P. and Kellomäki, S., 1983. Effect of grouping of foliage on the withinstand and within-crown light regime: comparison of random and grouping canopy models. Agric. Meteorol., 28: 143-155.

Penning de Vries, F.W.T., 1974. Substrate utilization and respiration in relation to growth and maintenance in higher plants. Neth. J. Agric. Sci., 22: 40-44.

Penning de Vries, F.W.T., 1975. The cost of maintenance processes in plant cells. Ann. Bot., 39: 77-92.

Penning de Vries, F.W.T. and Van Laar, H.H. (Editors), 1982. Simulation of Plant Growth and Crop Production. Simulation Monogr., Pudoc, Wageningen, 308 pp.

Penning de Vries, F.W.T., Brunsting, A. and Van Laar, H.H., 1974. Products, requirements and efficiency of biosynthesis; a quantitative approach. J. Theor. Biol., 45: $339-377$.

Pienaar, L.V. and Turnbull, K.J., 1973. The Chapman-Richards generalization of von Bertalanffy's growth model for basal area growth and yield in even-aged stands. For. Sci., 19: 2-22.

Polster, H., 1950. Die physiologischen Grundlagen der Stofferzeugung im Walde. Bayerischer Landwirtschaftsverlag, München, $96 \mathrm{pp}$.

Reed, K.L., 1980. An ecological approach to modelling growth of forest trees. For. Sci., 26(1): 33-50.

Satterlund, D.R., 1983. Forest shadows: How much shelter in a shelterwood? For. Ecol. Manage., 5: 27-37.

Schneider, T.W. and Kreysa, J., 1981. Dynamische Wachstums- und Ertragsmodelle für die Douglasie und die Kiefer. Mitt. 135, Bundesforschungsanstalt für Forst- und Holzwirtschaft, Hamburg-Reinbek, 137 pp. 
Schumacher, F.X. and Hall, F.D.S., 1933. Logarithmic expression of timbertree volume. J. Agric. Res., 47(9): 719-734.

Tesch, S.D., 1981. The evolution of forest yield determination and site classification. For. Ecol. Manage., 3: 169-182.

Yoda, K., 1978. Estimation of community respiration. In: T. Kira, Y. Ono and T. Hosokawa (Editors), Biological Production in a Warm-Temperate Evergreen Oak Forest of Japan. JIBP Synth., 18: 112-131.

Yoda, K., Shinozaki, K., Ogawa, H., Hozumi, K. and Kira, T., 1965. Estimation of the total amount of respiration in woody organs of trees and forest communities. J. Biol. 16, Osaka City University, pp. 15-26. 
